\title{
Anita Wohlmann (2014). Aged Young Adults. Age Readings of Contemporary American Novels and Films. Bielefeld: Transcript Verlag, 261 pp. ISBN 9783837624830 (paperback)
}

\author{
Reviewed by Maricel Oró Piqueras*
}

In Aged Young Adults, Anita Wohlmann aims to explore an area within age studies that has received little attention so far: age awareness in characters that are in their twenties and thirties. Age critics tend to focus on old age, that is, from sixty years old onwards. By age-awareness, Wohlmann refers not only to the negative connotations that Western culture has attributed to old age and the aging process in general but also to those roles and behaviour, appearance and objectives, which are considered appropriate for a specific age. In that sense, Wohlmann's study represents a step forward in the study of age and aging from a cultural point of view. Departing from Janice Sokoloff's The Margin That Remains: A Study of Aging in Literature, Wohlmann extends Sokoloff's thesis by focusing on recent American novels and films that have appeared in the first decades of the new millennium. By looking at Joel Zwick's My Big Fat Greek Wedding, Sam Mendes's Away We Go, Miranda July's The Future and It Chooses You, Jonathan Franzen's The Corrections, Don DeLillo's Cosmopolis, Tom Perrotta's Little Children and Benjamin Kunkel's Indecision, Wohlmann discerns the narrative conventions as well as the cultural discourses through which the young characters of each of these works express a conflictual relationship to their

\footnotetext{
${ }^{1}$ Maricel Oró Piqueras, Department of English and Linguistics, University of Lleida, Lleida, Spain
} 
International Journal of Ageing and Later Life

chronological age, and analyses to what extent capitalism and consumer culture dictate the achievements each life stage presupposes.

The book is divided into five chapters in which seminal theories in age studies and life course studies are revised in conversation with the newest publications in the field that serve as a basis for a thorough analysis of the uses and abuses of age references and their implications in each of the fictional works analysed. The first chapter, "Age and Aging in Theory and Practice," revises the concept of Bildungsroman as one of those "invisible narrative practices" that Margaret M. Gullette describes as naturalising age expectations and conventions and juxtaposes it to the "coming-ofage narratives" (2014: 46). In her analysis of coming-of-age narratives, Wohlmann refers to those invisible expressions and connotations on temporality and timing in which age awareness and age appropriateness are implicit. Another important concept that Wohlmann revises in the first chapter is the concept of age as a "movable marker" (2014:50) that calls attention to expressions such as "age performance," "age accomplishment" and "age coding," which prove age to be a constructed category that contemporary society tries to relate to "coherent and meaningful" (2014: 62) narratives of the self. This pinning down of concepts related to conceptions of age and ageing is a refreshing way of reviewing the literature on the topic that has been published in the last 20 years and setting the ground for the analysis of the young old characters.

The second chapter analyses Zwick's My Big Fat Greek Wedding and Mendes's Away We Go with a special focus on the aged young adults portrayed in these films. In Zwick's film, 30-year-old Toula is haunted by the figure of her grandmother as an old, unattractive, and demented woman, and she keeps on postponing entering into a normative adult life. In Mendes's Away We Go, Burt and Verona, both in their early thirties, are presented as "delayed adults" who try to find their path to maturation while they reflect on their conflictual relationship with time after they find out they are going to have a baby. The third chapter presents a revision of the shifting meanings of adulthood in American society which surfaced in the 1970s with the oil crises. Within that background, the delayed adulthood of the young protagonists in Perrotta's Little Childen and the premature ageing of the young protagonist in Franzen's The Corrections 
exemplify the blurring of life stages and challenge the cultural implications of youth, adulthood and old age. Despite looking and being chronologically young, the characters in these fictional texts feel old and inadequate. In that sense, Aged Young Adults proves the extent to which Western society has attached negative connotations to old age, and how well these are ingrained in our cultural imaginary and have a powerful impact on conceiving ourselves and our life course.

In the fourth chapter, interesting relationships are established between mental health and age, on the one hand, and liberal capitalism and consumer culture, on the other. In a time in which individuals are held responsible for constructing definitions of the self, their lifestyles, lives and career decisions, terms such as success and failure occupy centre stage. In this sense, what is age appropriate is very much related to the success a character is supposed to have achieved at a certain age. In the case of Kunkel's Indecision and DeLillo's Cosmopolis, the young characters position themselves in relation to the ideal of successful entrepreneurship. Whereas Dwight Wilmerding in Kunkel's novel is the perfect example of a failed entrepreneur who feels like an outsider unable to conform to the cultural expectations of his age and social status, the hero in DeLillo's Cospomolis constitutes the prototypical successful entrepreneur until he realises he cannot fight mortality. Decline, time acceleration and obsolescence are the words that not only define the accelerated ageing processes of these characters but also characterise our contemporary world.

The fifth chapter explores more positive imaginaries to a world defined by decline as the only alternative beyond youth. According to Wohlmann, July's The Future makes its characters and, by extension, the audience negotiate "accelerated and frozen time" (2014: 229) as well as their future selves in order to face alternative imaginaries to the decline narrative. By crossing the boundaries of reality and illusion, genres and format conventions, as well as through the use of playfulness and magic, July allows the aged young adult characters question and re-evaluate time, the future and ageing as synonymous with decline and loss. In her conclusion, Wohlmann acknowledges the loaded implications of age references at a metaphoric level, which are usually overlooked or unnoticed both in fictional works and in day-to-day interactions. In this respect, the analysis of age presented 
International Journal of Ageing and Later Life

in this book involves narratives about time, death and decline that are not exclusive to characters in their old age but which are prevalent throughout the life course. Moreover, looking at fictional texts constitutes a fruitful way of reflecting upon existent imaginaries and trying to come up with alternative ones.

\section{References}

Gullette, M. M. (2011). Agewise: Fighting the New Ageism in America. Chicago: University of Chicago Press.

Wohlmann, A. (2014). Aged Young Adults. Age Readings of Contemporary American Novels and Films. Bielefed: Transcript Verlag. 